\title{
A Preliminary Analysis of Small Spacecraft Finite-Thrust Aeroassisted Orbital Transfer
}

\author{
Begüm Şenses* \\ Anil V. Rao ${ }^{\dagger}$ \\ Department of Mechanical and Aerospace Engineering \\ University of Florida \\ Gainesville, FL 32611-6250
}

The problem of finite-thrust small spacecraft minimum-fuel heat rateconstrained aeroassisted orbital transfer between two low-Earth orbits with inclination change is considered. The trajectory design for a vehicle of small mass and moderate thrust is described in detail and the aeroassisted orbital transfer is posed as a nonlinear optimal control problem. The optimal control problem is solved using a previously developed open-source pseudospectral optimal control software. It is found for heating rate-unconstrained cases that the fuel consumption is insensitive to the number of atmospheric passes, whereas for heating rate-constrained cases the fuel consumption decreases as a function of the number of atmospheric passes. The key features of the optimal trajectories are identified. The result of this research demonstrates the efficiency of an aeroassisted orbital transfer as compared with an all-propulsive transfer and show the more realistic results obtained when compared with an aeroassisted orbital transfer where it is assumed that the thrust is impulsive.

\section{Nomenclature}

$\begin{array}{ll}a & =\text { Semi-Major Axis (m) } \\ C_{D} & =\text { Coefficient of Drag (no units) } \\ C_{D 0} & =\text { Zero-Lift Coefficient of Drag (no units) } \\ C_{L} & =\text { Coefficient of Lift (no units) }\end{array}$

*PhD Student, Department of Mechanical and Aerospace Engineering. Email: bgmsenses@ufl.edu.

${ }^{\dagger}$ Associate Professor, Department of Mechanical and Aerospace Engineering. Associate Fellow, AIAA. E-mail: anilvrao@ufl.edu. Corresponding Author. 


\begin{tabular}{|c|c|}
\hline $\bar{C}_{L}$ & $=$ Maximum Allowable Lift Coefficient (no units) \\
\hline$e$ & $=$ Eccentricity (no units) \\
\hline$g$ & $=$ Magnitude of Gravitational Acceleration $\left(\mathrm{m} \cdot \mathrm{s}^{-2}\right)$ \\
\hline$g_{0}$ & $=$ Standard Acceleration Due to Gravity $\left(\mathrm{m} \cdot \mathrm{s}^{-2}\right)$ \\
\hline$h$ & $=$ Altitude Over Spherical Earth $(\mathrm{m}$ or $\mathrm{km})$ \\
\hline$h_{\text {atm }}$ & $=$ Altitude at Edge of Sensable Atmosphere $(\mathrm{m}$ or $\mathrm{km})$ \\
\hline$i$ & $=$ Inclination $(\mathrm{rad}$ or $\mathrm{deg})$ \\
\hline$i_{f}$ & $=$ Inclination at Terminal Orbit (rad or deg) \\
\hline$I_{s p}$ & $=$ Specific Propulsion $(\mathrm{s})$ \\
\hline$K$ & $=$ Drag Polar Constant (no units) \\
\hline$m$ & $=$ Mass of Small Spacecraft $(\mathrm{kg})$ \\
\hline$n$ & $=$ Number of Atmospheric Passes (no units) \\
\hline$q$ & $=$ Dynamic Pressure $\left(\mathrm{N} \cdot \mathrm{m}^{-2}\right)$ \\
\hline$\dot{Q}$ & $=$ Stagnation Point Heating Rate $\left(\mathrm{W} \cdot \mathrm{cm}^{-2}\right)$ \\
\hline$\dot{Q}_{\max }$ & $=$ Maximum Stagnation Point Heating Rate $\left(\mathrm{W} \cdot \mathrm{cm}^{-2}\right)$ \\
\hline$\dot{Q}_{f}$ & $=$ Stagnation Point Heating Rate Multiplier $\left(\mathrm{W} \cdot \mathrm{cm}^{-2}\right)$ \\
\hline$r$ & $=$ Geocentric Radius $(\mathrm{m})$ \\
\hline$S$ & $=$ Vehicle Reference Area $\left(\mathrm{m}^{2}\right)$ \\
\hline$t$ & $=$ Time $(\mathrm{s})$ \\
\hline$\Delta t_{\mathrm{atm}}$ & $=$ Total Duration of Atmospheric Flight $(\mathrm{s})$ \\
\hline$T$ & $=$ Thrust Magnitude $(\mathrm{N})$ \\
\hline$\left(u_{1}, u_{2}, u_{3}\right)$ & $=$ Components of Thrust Direction (no units) \\
\hline$v$ & $=$ Speed $\left(\mathrm{m} \cdot \mathrm{s}^{-1}\right.$ or $\left.\mathrm{km} \cdot \mathrm{s}^{-1}\right)$ \\
\hline$\left(w_{1}, w_{2}\right)$ & $=$ Components of Lift Vector (no units) \\
\hline$v_{c}$ & $=$ Earth Radius Circular Speed of Spacecraft $\left(\mathrm{m} \cdot \mathrm{s}^{-1}\right)$ \\
\hline$R_{e}$ & $=$ Radius of Earth $(\mathrm{m})$ \\
\hline$\alpha$ & $=$ Angle of Attack (deg or rad) \\
\hline$\beta$ & $=$ Inverse of Density Scale Height $\left(\mathrm{m}^{-1}\right)$ \\
\hline$\gamma$ & $=$ Flight Path Angle (deg or rad) \\
\hline$\Delta i_{\mathrm{atm}}$ & $=$ Total Atmospheric Inclination Change (rad or deg) \\
\hline$\theta$ & $=$ Longitude $(\mathrm{rad})$ \\
\hline$\mu$ & $=$ Gravitational Parameter $\left(\mathrm{m}^{3} \cdot \mathrm{s}^{-2}\right)$ \\
\hline$\nu$ & $=$ True Anomaly (rad) \\
\hline$\rho$ & $=$ Atmospheric Density $\left(\mathrm{kg} \cdot \mathrm{m}^{-3}\right)$ \\
\hline$\rho_{0}$ & $=$ Atmospheric Density at Sea Level $\left(\mathrm{kg} \cdot \mathrm{m}^{-3}\right)$ \\
\hline$\Omega$ & $=$ Longitude of Ascending Node $(\mathrm{rad})$ \\
\hline$\omega$ & $=$ Argument of Perigee $(\mathrm{rad})$ \\
\hline$\sigma$ & $=$ Bank Angle (deg or rad) \\
\hline$\psi$ & $=$ Heading Angle $(\mathrm{rad})$ \\
\hline$\phi$ & $=$ Geocentric Latitude $(\mathrm{rad})$ \\
\hline
\end{tabular}




\section{Introduction}

It is well known that using aerodynamic force to transfer a spacecraft between two orbits can potentially reduce propellant consumption when compared with performing the orbital transfer using purely propulsive maneuvers. The use of aerodynamic force to perform an orbital transfer is generically called an aeroassisted orbital transfer, and the concept of an aeroassisted orbital transfer originates with the work of Ref. 1. Aeroassisted orbital transfer maneuvers fall into the following categories: aerobrake, aerocapture, aeroglide, aerocruise, and aerogravity assist. An aerobrake is a purely aerodynamic maneuver where the atmosphere is used to reduce the size of the orbit. An aerocapture is an atmospheric maneuver that depletes a sufficient amount of energy to change the orbit from hyperbolic to elliptic relative to the centrally attracting body. An aeroglide typically combines unpowered atmospheric flight with powered exo-atmospheric flight to change the size, shape, and orientation of the orbit. An aerocruise is a maneuver that combines the use of atmospheric force with thrusting in the atmosphere. Finally, an aerogravity assist combines the atmosphere with propulsion and gravity to modify a hyperbolic orbit (that is, an aerogravity assist is an aerodynamically assisted planet swing-by).

Early work on aeroassisted orbital transfer for large spacecraft is summarized in the survey papers of Refs. 2 and 3. Since that time, a great deal more work has been done on the problem of aeroassisted orbital transfer and guidance for large spacecraft. ${ }^{4-17}$ Ref. 4 considers the problem of minimum energy loss while completing an aeroassisted plane change. Refs. 5 and 6 consider the problem of high-Earth orbit to low-Earth orbit impulsive single-pass liftmodulated aeroassisted orbital transfer. Ref. 7 develops a neighboring optimal guidance law that controls fuel consumption in an aeroassisted orbital transfer vehicle. Ref. 8 considers the problem of optimal heating rate-constrained solutions using an aeroassisted orbital transfer. Ref. 9 studies the problem of optimal skip trajectories using the atmosphere. Ref. 10 performs a numerical optimization study using direct collocation for the problem of low-Earth orbit aeroassisted orbital transfer with plane change in the presence of heating rate and heat load constraints. Ref. 11 performs a numerical optimization study of coplanar aeroassisted orbital transfer, while Ref. 12 considers the problem of aeroassisted orbital transfer with limits on thrust. Ref. 13 considers the problem of geostationary to low-Earth orbit transfer using aerogliding maneuvers and multiple passes through the atmosphere in the presence of constraints on heating rate. Ref. 14 considers coplanar and non-coplanar trajectory transfers using solar electric propulsion and aeroassisted maneuvers. Ref. 15 considers the problem of developing a fast method that can be used in multi-disciplinary design optimization of aeroassisted orbital transfer. Ref. 16 studies the sensitivity of minimum-fuel aeroassisted orbital transfer to thermal protection system mass, while Ref. 17 develops a multi-disciplinary design optimization method for use in preliminary design of aeroassisted orbital transfer.

While earlier work focused on orbital transfer of large spacecraft, in recent the use of small spacecraft has been recognized as a technology that than greatly increase the operational responsiveness of space. ${ }^{18,19}$ One way in which operational responsiveness can be improved is for small spacecraft to have the ability to perform crossrange maneuvers using aerodynamic force, that is, it is useful for a small spacecraft to have the ability to perform an aeroassisted orbital transfer. The use of atmospheric force can potentially enhance an on-orbit maneuver (for example, inclination change) while simultaneously lowering fuel consumption, thereby reducing the overall cost of a mission as compared to using an all-propulsive orbital transfer. 
While the aforementioned research shows that large spacecraft aeroassisted orbital transfer has received a great deal of attention, significantly less attention has been paid to the problem of small spacecraft aeroassisted orbital transfer. One particular study of small spacecraft aeroassisted orbital transfer is the work of Ref. 20. Specifically, Ref. 20 considers the problem of minimum-fuel heating rate-constrained aeroassisted orbital transfer under the assumption of impulsive thrust. Because propulsion system limitations on board a small spacecraft make the assumption of impulsive thrust unrealistic, in this research we consider the problem of moderate finite-thrust aeroassisted orbital transfer of a small spacecraft with a mass of approximately $1000 \mathrm{~kg}$ (see Refs. 20-23).

The objective of this paper is to gain a better understanding of the performance requirements and the structure of minimum-fuel trajectories for transferring a small spacecraft with moderate thrust capability between two low-Earth orbits with a constraint on heating rate and a change in inclination. The optimal aeroassisted orbital transfer problem is posed as a nonlinear multiple-phase optimal control problem, and the optimal control problem is solved via direct collocation using the Radau collocation $h p$-adaptive ${ }^{24}$ version of the open-source optimal control software GPOPS. ${ }^{25-27}$ The overall performance of the vehicle is analyzed as a function of the number of atmospheric passes, required inclination change, and maximum allowable heating rate. The results obtained in this study are also compared against a finitethrust all-propulsive orbital transfer. Finally, the key features of the structure of the optimal trajectories are described in detail.

This paper is organized as follows. In Section II we state the equations of motion and physical model for the vehicle under consideration in this study. In Section III we provide a detailed description of the problem formulation. In Section IV we describe the results of the numerical optimization study. Finally, in Section V we provide conclusions on our work.

\section{Equations of Motion and Vehicle Model}

Consider the motion of a vehicle modeled as a point mass over a spherical non-rotating Earth. The vehicle can be in either unpowered exo-atmospheric flight, powered exo-atmospheric flight or unpowered atmospheric flight. During unpowered or powered exo-atmospheric flight, the differential equations of motion are given $\operatorname{as}^{28}$

$$
\begin{gathered}
\dot{r}=v \sin \gamma, \quad \dot{\theta}=\frac{v \cos \gamma \cos \psi}{r \cos \phi}, \quad \dot{\phi}=\frac{v \cos \gamma \sin \psi}{r}, \quad \dot{v}=\frac{T u_{1}}{m}-g \sin \gamma, \\
\dot{\gamma}=\frac{T u_{2}}{m v}-\left(\frac{g}{v}-\frac{v}{r}\right) \cos \gamma, \quad \dot{\psi}=\frac{T u_{3}}{m v \cos \gamma}-\frac{v}{r} \cos \gamma \cos \psi \tan \phi, \quad \dot{m}=\frac{-T}{g_{0} I_{s p}},
\end{gathered}
$$

where $g=\mu / r^{2}$. It is noted that during unpowered exo-atmospheric flight neither $T$ nor $\left(u_{1}, u_{2}, u_{3}\right)$ are included in the dynamics of Eq. (1). The equations of motion for the vehicle during unpowered atmospheric flight are given $\mathrm{as}^{28}$

$$
\begin{gathered}
\dot{r}=v \sin \gamma, \quad \dot{\theta}=\frac{v \cos \gamma \cos \psi}{r \cos \phi}, \quad \dot{\phi}=\frac{v \cos \gamma \sin \psi}{r}, \quad \dot{v}=-\frac{q S C_{D}}{m}-g \sin \gamma, \\
\dot{\gamma}=-\frac{q S}{m v} w_{1}-\left(\frac{g}{v}-\frac{v}{r}\right) \cos \gamma, \quad \dot{\psi}=-\frac{q S}{m v \cos \gamma} w_{2}-\frac{v}{r} \cos \gamma \cos \psi \tan \phi,
\end{gathered}
$$

where $q=\rho v^{2} / 2$ is the dynamic pressure, $\rho=\rho_{0} \exp (-\beta h), C_{D}=C_{D 0}+K C_{L}^{2}$, and $C_{L}=$ $\sqrt{w_{1}^{2}+w_{2}^{2}}$. Table 2 provides the physical constants and vehicle data used in this research, 
where the vehicle data in Table 2 represents a high lift-to-drag ratio moderate-thrust vehicle with aerodynamic characteristics similar to those found in Refs. 20 and 29.

Table 2. Physical Constants and Vehicle Data.

\begin{tabular}{|c|c|c|}
\hline Parameter & Units & Value \\
\hline$g_{0}$ & $\mathrm{~m} / \mathrm{s}^{2}$ & 9.80665 \\
\hline$R_{e}$ & $\mathrm{~m}$ & 6378145 \\
\hline$\mu$ & $\mathrm{m}^{3} / \mathrm{s}^{2}$ & $3.986012 \times 10^{14}$ \\
\hline$I_{S P}$ & $\mathrm{~s}$ & 310 \\
\hline$T$ & $\mathrm{~N}$ & 2500 \\
\hline $\bar{h}$ & $\mathrm{~km}$ & 110 \\
\hline$S$ & $\mathrm{~m}^{2}$ & 1 \\
\hline$m_{0}$ & $\mathrm{~kg}$ & 818 \\
\hline$\rho_{0}$ & $\mathrm{~kg} / \mathrm{m}^{3}$ & 1.225 \\
\hline$H$ & $\mathrm{~m}$ & 7200 \\
\hline$K$ & No Units & 1.4 \\
\hline$C_{L \alpha}$ & No Units & 0.5699 \\
\hline$C_{D 0}$ & No Units & 0.032 \\
\hline$\dot{Q}_{f}$ & W $/ \mathrm{cm}^{2}$ & 19987 \\
\hline
\end{tabular}

\section{Problem Formulation}

In this section we formulate the problem of transferring a small spacecraft, whose model is given in Section II, between two circular low-Earth orbits of the same size but with different inclination. During atmospheric flight it is assumed that the heating rate is constrained. The goal is to transfer the spacecraft from the initial orbit to the terminal orbit while minimizing the fuel consumption. In Section A we formulate the trajectory event sequence. In Section $\mathrm{B}$ we provide the initial and terminal conditions. In Section $\mathrm{C}$ we develop the interior-point constraints. In Section D we formulate the path constraints during flight. In Section E we develop the objective functional that is to be minimized. Finally, in Section F we state formally the multiple-phase optimal control problem that corresponds to the trajectory event sequence defined in Section A.

\section{A. Trajectory Event Sequence}

The trajectory event sequence for an $n$-pass transfer is given as follows. The orbital transfer starts with the following phase:

(i) a constant thrust powered exo-atmospheric flight phase that starts on the initial orbit and terminates at the altitude of the edge of the sensable atmosphere, $h_{\mathrm{atm}}$.

The following three phases and events are then repeated $n-1$ times:

(ii) an atmospheric flight phase that starts and terminates at the altitude $h_{\text {atm }}$; 
(iii) an unpowered exo-atmospheric flight phase that starts at the edge of the sensable atmosphere;

(iv) a constant thrust powered exo-atmospheric flight phase that terminates at the altitude $h_{\text {atm. }}$.

Finally, the trajectory event sequence terminates with the following three phases:

(v) an atmospheric flight phase that starts and terminates at the altitude $h_{\text {atm }}$;

(vi) an unpowered exo-atmospheric flight phase that starts at the altitude $h_{\text {atm }}$ and terminates at or prior to the terminal orbit;

(vii) a constant thrust powered exo-atmospheric flight phase that terminates at the terminal orbit.

\section{B. Initial and Terminal Conditions}

The initial conditions correspond to those of an equatorial circular orbit of altitude $h_{0}$. This initial orbit is given in terms of orbital elements as

$$
\begin{gathered}
a\left(t_{0}\right)=R_{e}+h_{0}, \quad e\left(t_{0}\right)=0, \quad i\left(t_{0}\right)=0, \\
\Omega\left(t_{0}\right)=0, \quad \omega\left(t_{0}\right)=0, \quad \nu\left(t_{0}\right)=0,
\end{gathered}
$$

where the values for $\Omega\left(t_{0}\right), \omega\left(t_{0}\right)$, and $\nu\left(t_{0}\right)$ are arbitrarily set to zero. The terminal conditions correspond to a circular orbit of altitude $h_{f}$ and are given as

$$
a\left(t_{f}\right)=R_{e}+h_{f}, \quad e\left(t_{f}\right)=0, \quad i\left(t_{f}\right)=i_{f},
$$

where $i_{f}$ is the prescribed inclination of the terminal orbit. Because the terminal orbit is circular and no constraints are placed on the location of the spacecraft in the terminal orbit, the values $\Omega\left(t_{f}\right)$ and $\omega\left(t_{f}\right)$ are undefined while the value $\nu\left(t_{f}\right)$ is free.

\section{Interior-Point Constraints}

The following interior-point constraints are imposed during the orbital transfer. First, at all phase boundaries it is assumed that the time, state, and mass are continuous, that is,

$$
\begin{gathered}
t_{f}^{-}=t_{0}^{+}, \quad r\left(t_{f}^{-}\right)=r\left(t_{0}^{+}\right), \quad \theta\left(t_{f}^{-}\right)=\theta\left(t_{0}^{+}\right), \quad \phi\left(t_{f}^{-}\right)=\phi\left(t_{0}^{+}\right), \\
v\left(t_{f}^{-}\right)=v\left(t_{0}^{+}\right), \quad \gamma\left(t_{f}^{-}\right)=\gamma\left(t_{0}^{+}\right), \quad \psi\left(t_{f}^{-}\right)=\psi\left(t_{0}^{+}\right), \quad m\left(t_{f}^{-}\right)=m\left(t_{0}^{+}\right),
\end{gathered}
$$

where $t_{f}^{-}$and $t_{0}^{+}$correspond to the final time of a phase and the initial time of the ensuing phase. Next, in order to ensure that the vehicle is descending upon atmospheric entry, the following constraints are imposed at each atmospheric entry:

$$
r\left(t_{0}^{\mathrm{atm}}\right)=h_{\mathrm{atm}}+R_{e}, \gamma\left(t_{0}^{\mathrm{atm}}\right) \leq 0,
$$

where $t_{0}^{\text {atm }}$ is the time at the start of any atmospheric flight segment. Next, in order to ensure that the vehicle is ascending upon atmospheric exit, the following constraints are imposed at each atmospheric exit:

$$
r\left(t_{f}^{\mathrm{atm}}\right)=h_{\mathrm{atm}}+R_{e}, \gamma\left(t_{f}^{\mathrm{atm}}\right) \geq 0,
$$

where $t_{f}^{\mathrm{atm}}$ is the time at the terminus of any atmospheric flight segment. 


\section{Path Constraints}

The following constraint is imposed during atmospheric flight in order to ensure that the vehicle does not exit the atmosphere:

$$
0 \leq h \leq h_{\text {atm }}
$$

Furthermore, It is assumed during atmospheric flight that the coefficient of lift is constrained as

$$
0 \leq w_{1}^{2}+w_{2}^{2} \leq \bar{C}_{L}^{2}
$$

Next, it is assumed that the vehicle is heating rate-constrained during atmospheric flight. In this research the heating rate is modeled using the stagnation point heating rate model from Ref. 30 as

$$
\dot{Q}=\dot{Q}_{f}\left(\rho / \rho_{0}\right)^{0.5}\left(v / v_{c}\right)^{3.15}
$$

where $\dot{Q}_{f}$ is a positive constant and $v_{c}=\sqrt{\mu / R_{e}}$. The stagnation point heating rate constraint is then given as

$$
0 \leq \dot{Q} \leq \dot{Q}_{\max }
$$

While in principle Eq. (11) can be implemented directly, it was found in Ref. 20 that it is more computationally tractable to constrain the natural logarithm of Eq. (11), that is,

$$
-\infty \leq \log \dot{Q}_{f}-0.5 h / H+3.15 \log \left(v / v_{c}\right) \leq \log \dot{Q}_{\max }
$$

Finally, during exo-atmospheric flight the only path constraint is that the thrust direction must be unit vector, that is,

$$
u_{1}^{2}+u_{2}^{2}+u_{3}^{2}=1
$$

\section{E. Objective Functional}

The objective of the optimal control problem is to minimize the fuel consumption during the transfer. This objective is stated equivalently as maximizing the mass at the final time, that is

$$
J=-m\left(t_{f}\right) .
$$

\section{F. Optimal Control Problem}

The optimal control problem corresponding to the multiple-pass aeroassisted orbital transfer problem described in Sections II and III is stated as follows. Determine the trajectory and control of the vehicle that follows the trajectory event sequence given in Section A while minimizing the objective functional of Eq. (14) and satisfying the dynamic constraints of Section II, the initial and terminal conditions of Section B, the interior-point constraints of Section C, and the path constraints of Section D. The optimal control aeroassisted orbital transfer problem was solved using the open-source optimal control software GPOPS ${ }^{25}$ using the nonlinear programming problem solver SNOPT and the automatic differentiator INTLAB. All computations were performed using MATLAB-R2010b on a MacBook Pro 2.53 GHZ Core 2 Duo running Mac OS X 10.6.7. 


\section{Results}

The optimal control problem described in Section III was solved for $n=(1,2,3)$ atmospheric passes with terminal inclinations $i_{f}=(20,30,40)$ deg and maximum allowable stagnation point heating rates $\dot{Q}_{\max }=(\infty, 600,400,200) \mathrm{W} \cdot \mathrm{cm}^{-2}$. The results are divided into two parts. First, the overall performance is described both with and without a constraint on the stagnation point heating rate, while the second set of results shows the structure of the heating rate-unconstrained and heating rate-constrained optimal trajectories. With regard to the overall performance, the aeroassisted orbital transfer is compared with an all-propulsive transfer (that is, a transfer where the atmosphere is not utilized but, instead, the orbit is changed using finite-thrust propulsion). The all-propulsive transfer consists of a constant thrust powered exo-atmospheric flight phase that starts on the initial orbit and terminates on the final orbit with the required inclination change. It is noted that the all-propulsive transfer was also solved using GPOPS. ${ }^{25}$

\section{A. Performance}

Figure 1 shows the final mass fraction, $m\left(t_{f}\right) / m_{0}$, as a function of the number of atmospheric passes, $n$, and final inclination, $i_{f}$, for $Q_{\max }=(\infty, 600,400,200) \mathrm{W} / \mathrm{cm}^{2}$, where $n=0$ indicates the aforementioned all-propulsive transfer. It is seen from Fig. 1(a) that, for a fixed value of $i_{f}$, the final mass fraction is essentially constant as a function of $n$ when the heating rate is unconstrained. Moreover, examining the heating rate-constrained mass fractions as given in Figs. 1(b)-1(d), it is seen that when the heating rate is constrained, less fuel is consumed using multiple atmospheric passes over using a single atmospheric pass. Moreoever, the benefit of using multiple atmospheric passes is approximately the same regardless of the value of $\dot{Q}_{\max }$. As a result, using multiple atmospheric passes has a slight but noticeable benefit over using a single atmospheric pass. In addition, Figs. 1(a)-1(d) show that $m\left(t_{f}\right) / m_{0}$ decreases as $\dot{Q}_{\max }$ decreases, and this rate of decrease is essentially the same regardless of the value of $i_{f}$. Finally, it is seen in all cases that the fuel consumed using the aeroassisted orbital transfer is significantly less than the fuel consumed using the all-propulsive $(n=0)$ transfer. Finally, Fig. 2 shows the total amount of inclination change performed by the atmosphere, $\Delta i_{\text {atm }}$, as a function of $\dot{Q}_{\max }$ and $i_{f}$. When the heating rate unconstrained, $\Delta i_{\text {atm }}$ is essentially constant as a function of $n$. When the heating rate is constrained, however, $\Delta i_{\text {atm }}$ increases slightly as $n$ increases. Moreover, it is seen that the slope of $\Delta i_{\text {atm }}$ as a function of $n$ increases significantly as $i_{f}$ increases. As a result, it becomes much more beneficial to utilize the atmosphere for the cases where the heating rate is constrained and $i_{f}$ is large as compared to the cases where the heating rate is unconstrained or the heating rate is constrained but $i_{f}$ is small. 




(a) $\dot{Q}_{\max }=\infty$.

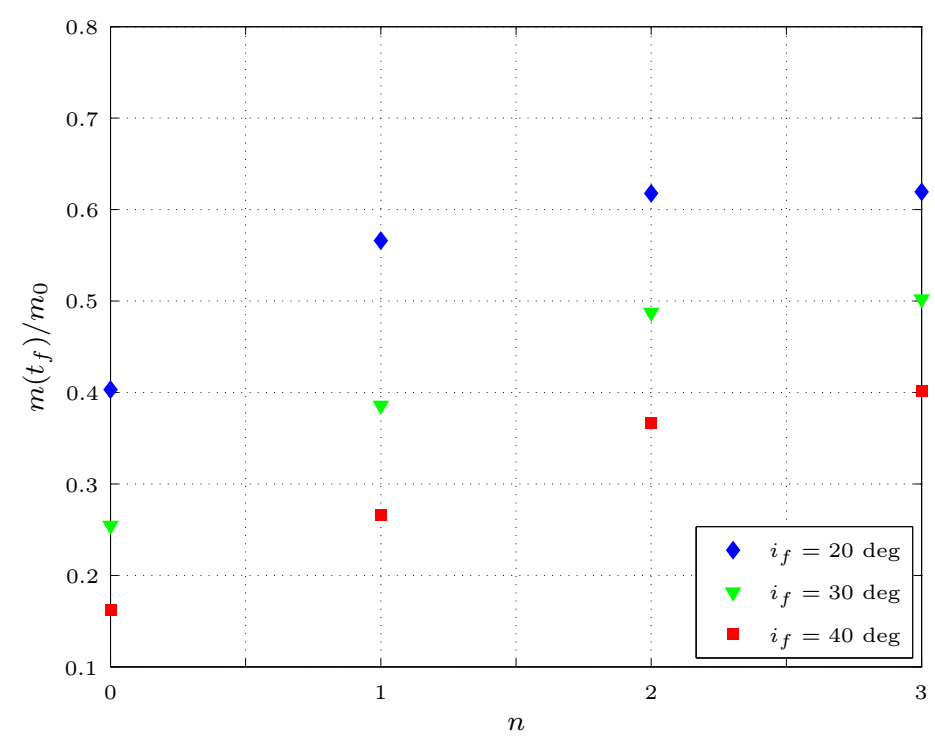

(c) $\dot{Q}_{\max }=400 \mathrm{~W} / \mathrm{cm}^{2}$.



(b) $\dot{Q}_{\max }=600 \mathrm{~W} / \mathrm{cm}^{2}$.

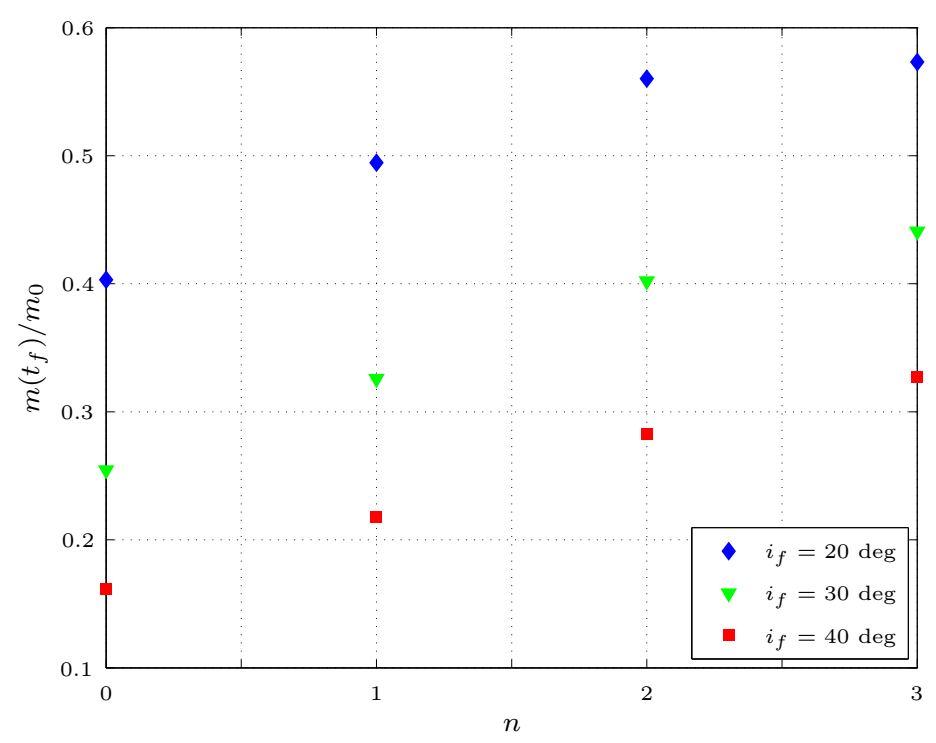

(d) $\dot{Q}_{\max }=200 \mathrm{~W} / \mathrm{cm}^{2}$.

Figure 1. Final Mass Fraction, $m\left(t_{f}\right) / m_{0}$, vs. Number of Atmospheric Passes, $n$, Maximum Allowable Stagnation Point Heating Rate, $\dot{Q}_{\max }$, and Terminal Inclination, $i_{f}$. 


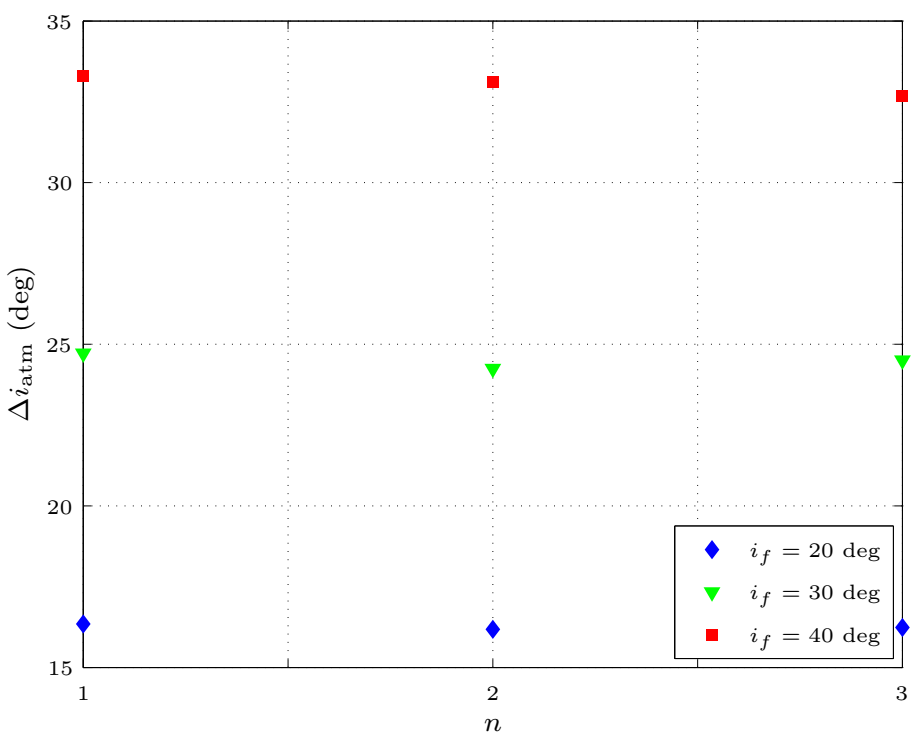

(a) $\dot{Q}_{\max }=\infty$.

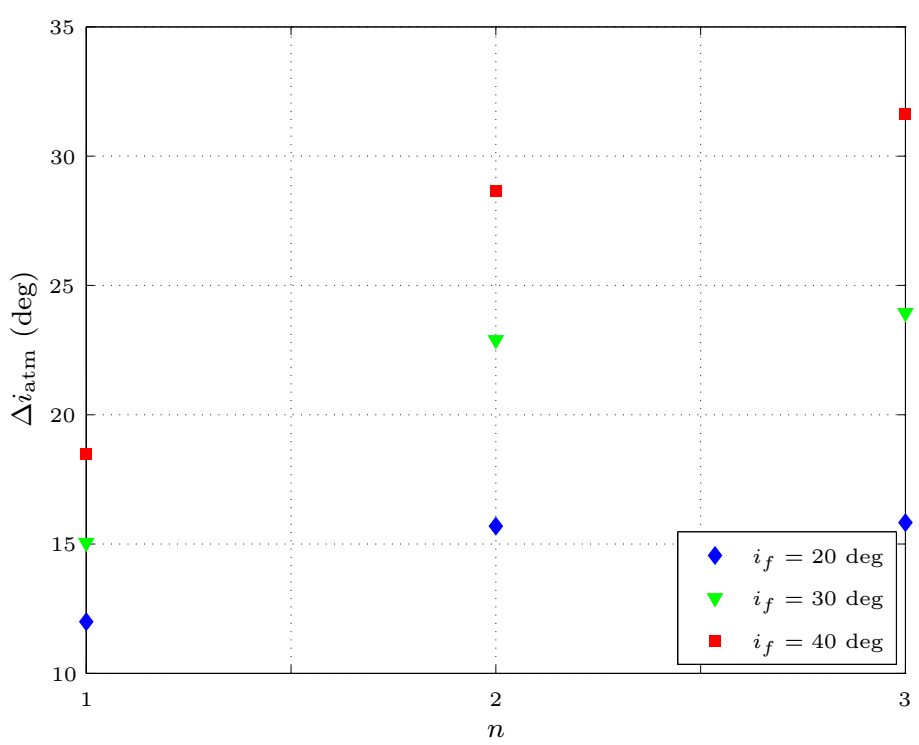

(c) $\dot{Q}_{\max }=400 \mathrm{~W} / \mathrm{cm}^{2}$.

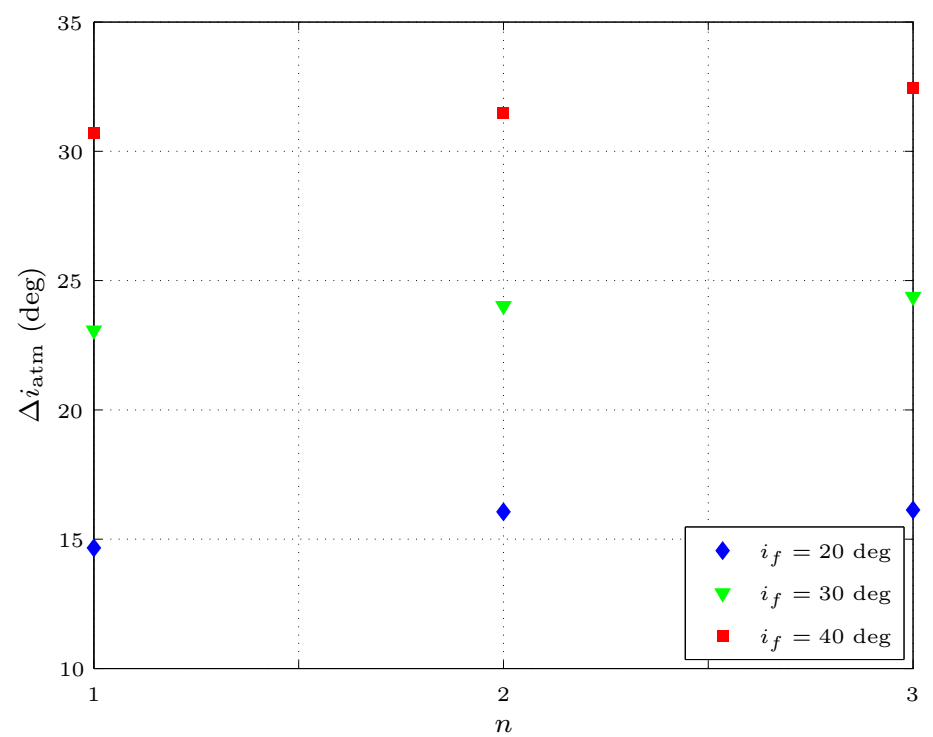

(b) $\dot{Q}_{\max }=600 \mathrm{~W} / \mathrm{cm}^{2}$.

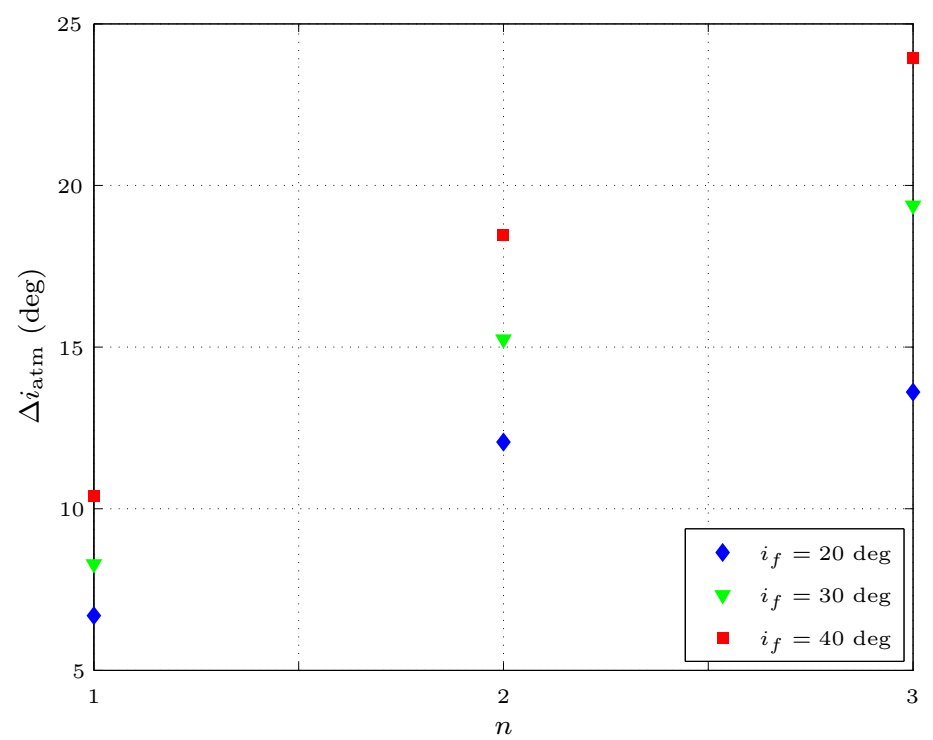

(d) $\dot{Q}_{\max }=200 \mathrm{~W} / \mathrm{cm}^{2}$.

Figure 2. Total Atmospheric Inclination Change, $\Delta i_{\text {atm }}$, vs. Number of Atmospheric Passes, $n$, Maximum Allowable Stagnation Point Heating Rate, $\dot{Q}_{\max }$, and Terminal Inclination, $i_{f}$. 


\section{B. Key Features of Optimal Trajectories}

Solutions obtained for a single atmospheric pass $(n=1)$ with no constraint on heating rate are now examined. Figure 3(a) shows $h$ vs. $v$ during atmospheric flight for different values of $i_{f}$, where it is seen that the speed at atmospheric entry is essentially the same regardless of the value of $i_{f}$, while the speed at atmospheric exit decreases as $i_{f}$ increases. Next, Fig. 3(b) shows $h$ vs. $\gamma$ during atmospheric flight. While the flight path angle at atmospheric entry is essentially constant as a function of $i_{f}$, the flight path angle at atmospheric exit increases moderately as a function of $i_{f}$. The decrease in speed and increase in flight path angle at atmospheric exit are expected because use of the atmosphere increases as a function of $i_{f}$ and that requires the vehicle to dive more for larger $i_{f}$. Moreover, examining, 3(c), that gives $h$ vs. $\dot{Q}$, shows that the maximum heating rate increases as $i_{f}$ increases, and it is noted that $\dot{Q}$ is a maximum when $h$ is a minimum. Next, Figs. 4(a), and 4(b) show, respectively, the angle of attack, $\alpha$, and the bank angle, $\sigma$, vs. $t$ during atmospheric flight for different values of $i_{f}$. it is seen that the angle of attack profiles are similar for all values of $i_{f}$ with the key exception that for $i_{f}=20$ deg the angle of attack does not increase near the end of atmospheric flight. The reason why the angle of attack increases for the larger values of $i_{f}$ is that the lift required to exit the atmosphere is larger when $i_{f}$ is larger, thus requiring a larger value of $\alpha$. Next, it is seen that for all cases the bank angle starts at approximately $-180 \mathrm{deg}$ and terminates at approximately $-60 \mathrm{deg}$. The initial bank angle of $-180 \mathrm{deg}$ corresponds to a downward pointing lift, resulting in the vehicle descending at the start of atmospheric flight. As the vehicle progresses through atmospheric flight, the bank angle quickly passes from $-180 \mathrm{deg}$ to $-60 \mathrm{deg}$, resulting in a sideways pointing vehicle and allowing for lateral motion to change the inclination. The fact that the bank angle terminates with with $-60 \mathrm{deg}$ is consistent with the fact that the vehicle must be ascending as it leaves the atmosphere, thus requiring that the bank angle at atmospheric exit be greater than -90 deg. 


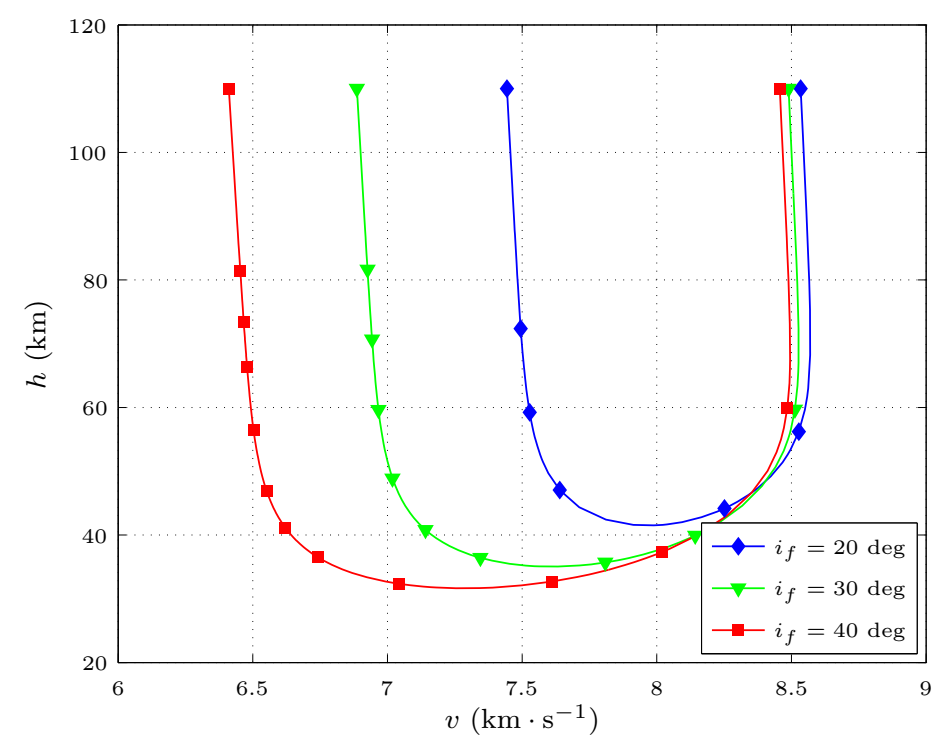

(a) $h$ vs. $v$.

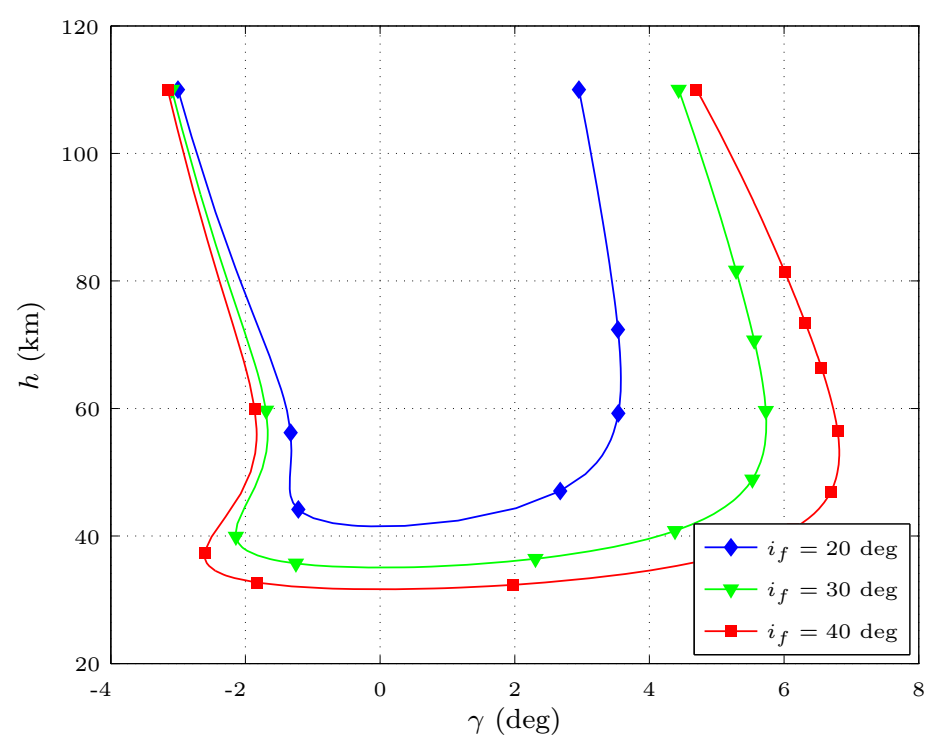

(b) $h$ vs. $\gamma$.

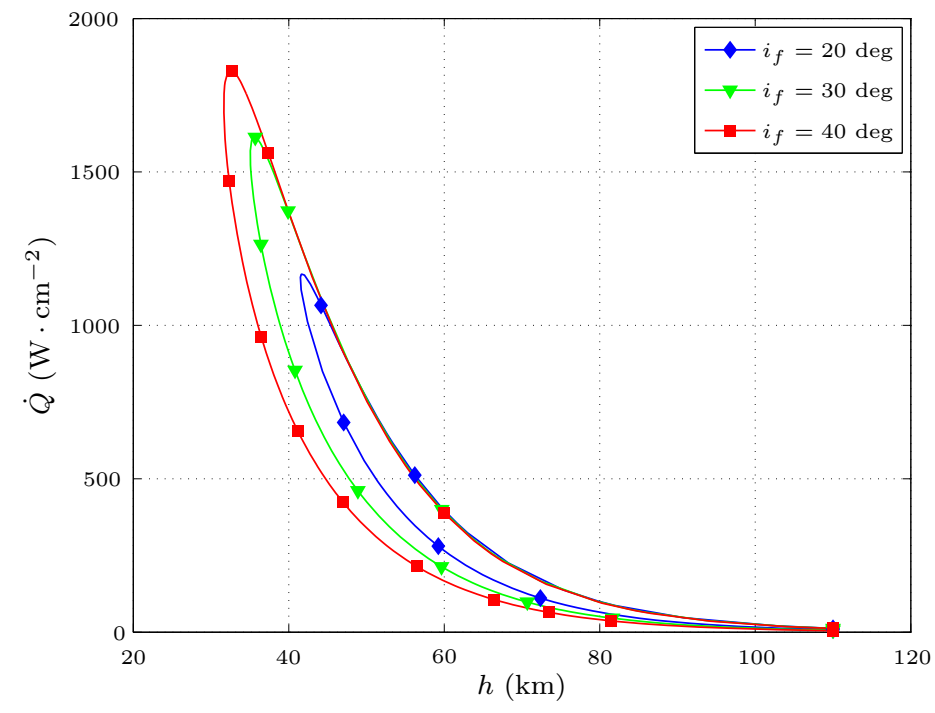

(c) $\dot{Q}$ vs. $h$.

Figure 3. Altitude, $h$, vs. Speed, $v$, Altitude, $h$, vs. Flight Path Angle, $\gamma$, and Stagnation Point Heating Rate, $\dot{Q}$, vs. Altitude, $h$, During Atmospheric Flight for One Atmospheric Pass, $n=1$, and Terminal Inclinations $i_{f}=(20,30,40)$ deg with No Constraint on Heating Rate. 


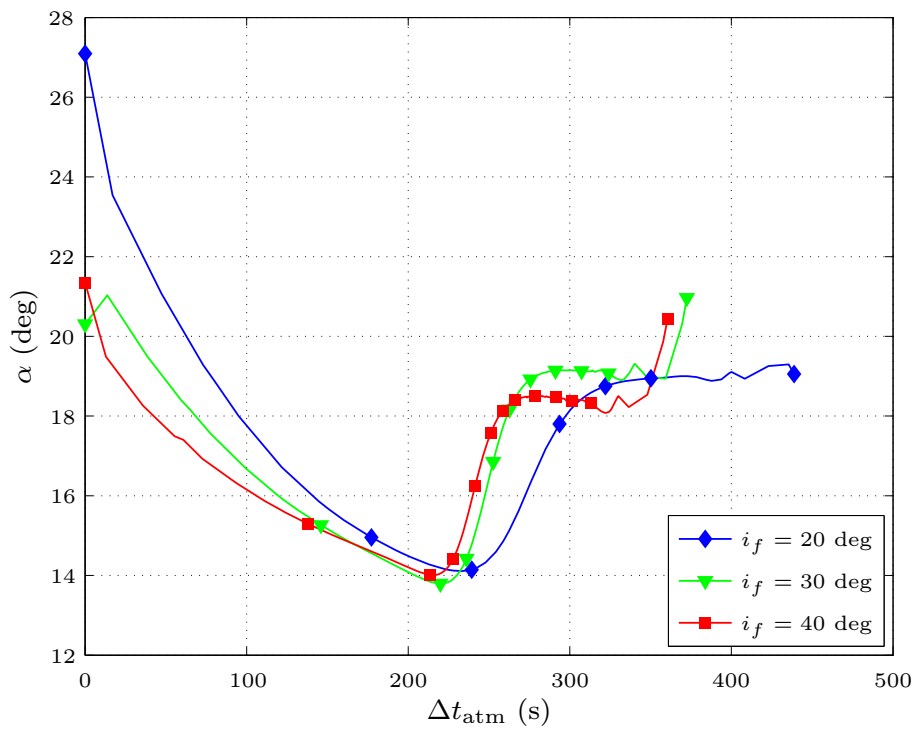

(a) $\alpha$ vs. $\Delta t_{\text {atm }}$.

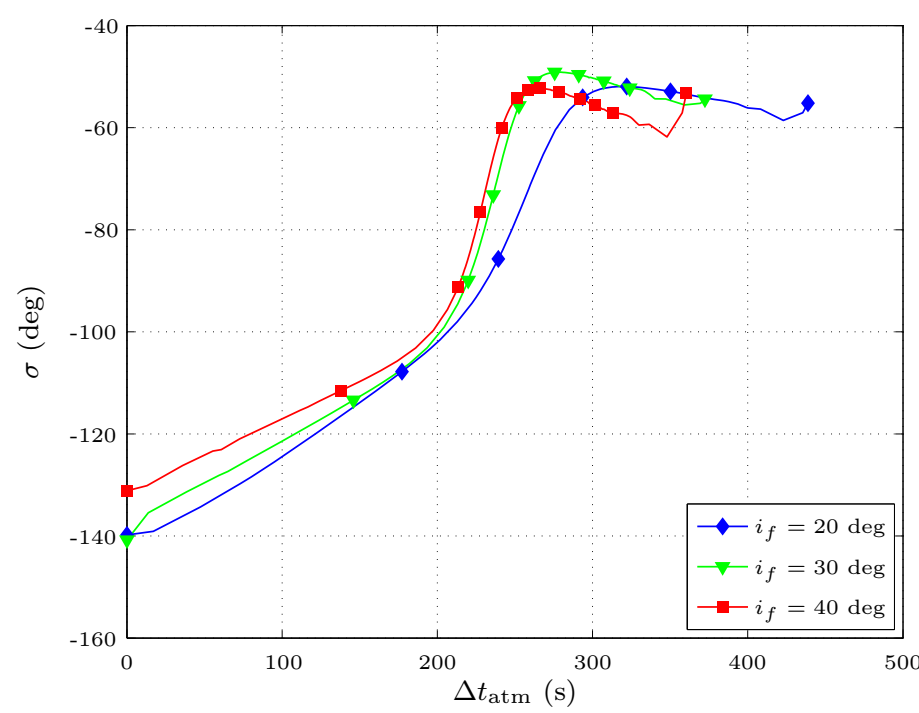

(b) $\sigma$ vs. $\Delta t_{\text {atm }}$.

Figure 4. Angle of Attack, $\alpha$, and Bank Angle, $\sigma$ vs. Time Since Atmospheric Entry, $\Delta t_{\text {entry }}$, for One Atmospheric Pass, $n=1$, and Terminal Inclinations $i_{f}=(20,30,40)$ deg with No Constraint on Heating Rate. 


\section{Conclusions}

The problem of finite-thrust small spacecraft minimum-fuel heating rate-constrained aeroassisted orbital transfer between two low-Earth orbits with inclination change has been considered. The trajectory event sequence was described in detail for a vehicle with small mass and moderate thrust capability. The aeroassisted orbital transfer was then posed as a multiple-phase optimal control problem. The optimal control problem was then solved using an established open-source general-purpose optimal control software. The results of this study show that low-Earth orbital transfer of a small spacecraft with moderate thrust can be accomplished in a more fuel-efficient manner using an aeroassisted orbital transfer as compared to using an all-propulsive orbital transfer.

\section{Acknowledgments}

The authors gratefully acknowledge support for this research from the the U.S. Office of Naval Research under Grant N00014-11-1-0068 and the Scientific and Technical Research Council of Turkey.

\section{References}

${ }^{1}$ London, H. S., "Change of Satellite Orbit Plane by Aerodynamic Maneuvering," IAS 29th Annual Meeting, International Astronautical Society, New York, January 1961.

${ }^{2}$ Walberg, G. D., "A Survey of Aeroassisted Orbit Transfer," Journal of Spacecraft and Rockets, Vol. 22, No. 1, 1985, pp. 3-18.

${ }^{3}$ Mease, K. D., "Aerossisted Orbital Transfer: Current Status," The Journal of the Astronautical Sciences, Vol. 36, No. 1/2, 1988, pp. 7-33.

${ }^{4}$ Hull, D. G., Giltner, J. M., Speyer, J. L., and Mapar, J., "Minimum Energy-Loss Guidance for Aeroassisted Orbial Plane Change," Journal of Guidance, Control, and Dynamics, Vol. 8, No. 4, 1985, pp. 487-493.

${ }^{5}$ Miele, A. and Venkataraman, P., "Optimal Trajectories for Aeroassisted Orbital Transfer," Acta Astronautica, Vol. 11, No. 7-8, July-August 1984, pp. 423-433.

${ }^{6}$ Miele, A., Wang, T., and Deaton, A. W., "Properties of the Optimal Trajectories for Coplanar, Aeroassisted Orbital Transfer," Journal of Optimization Theory and Applications, Vol. 69, No. 1, April 1991, pp. 1-30.

${ }^{7}$ Naidu, D. S., "Neighboring Optimal Guidance for Aeroassisted Orbital Transfer," IEEE Transactions on Aerospace and Electronic Systems, Vol. 29, No. 3, July-September 1993, pp. 656-665.

${ }^{8}$ Seywald, H., "Variational Solutions for the Heat-Rate-Limited Aeroassisted Orbital Transfer Problem," Journal of Guidance, Control, and Dynamics, Vol. 19, No. 3, May-June 1996, pp. 686-692.

${ }^{9}$ Vinh, N. and Shih, Y., "Optimum Multiple-Skip Trajectories," Acta Astronautica, Vol. 41, No. 2, July 1997, pp. 103-112.

${ }^{10}$ Zimmerman, F. and Calise, A. J., "Numerical Optimization Study of Aerassisted Orbital Transfer," Journal of Guidance, Control, and Dynamics, Vol. 21, No. 1, January-February 1998, pp. 127-133.

${ }^{11}$ Baumann, H. and Oberle, H., "Numerical Computation of Optimal Trajectories for Coplanar, Aeroassisted Orbital Transfer," Journal of Optimization Theory and Applications, Vol. 107, No. 3, December 2000, pp. 457-479.

${ }^{12}$ Baumann, H., "Thrust Limited Coplanar Aeroassisted Orbital Transfer," Journal of Guidance, Control, and Dynamics, Vol. 24, No. 4, July-August 2001, pp. 732-738.

${ }^{13}$ Rao, A. V., Tang, S., and Hallman, W. P., "Numerical Optimization Study of Multiple-Pass Aeroassisted Orbital Transfer," Optimal Control Applications and Methods, Vol. 23, No. 4, July-August 2002, pp. 215-238. 
${ }^{14}$ Trask, A. and Coverstone, V., "Optimal Low-Thrust Trajectories Combined with an Aeroassist Maneuver," Journal of Spacecraft and Rockets, Vol. 41, No. 4, July-August 2004, pp. 629-634.

${ }^{15}$ Berend, N., Bertrand, S., and Jolly, C., "Optimization Method for Mission Analysis of Aeroassisted Orbital Transfer Vehicles," Aerospace Science and Technology, Vol. 11, No. 5, June 2007, pp. $432-441$.

${ }^{16}$ Gogu, C., Matsumura, T., Haftka, R. T., and Rao, A. V., "Aeroassisted Orbital Transfer Trajectory Optimization Considering Thermal Protection System Mass," Journal of Guidance, Control, and Dynamics, Vol. 32, No. 3, May-June 2009, pp. 927-938.

${ }^{17}$ Berend, N. and Bertrand, S., "MDO approach for early design of aerobraking orbital transfer vehicles," Acta Astronautica, Vol. 65, No. 11-12, December 2009, pp. 1668-1678.

${ }^{18}$ Brown, K. K., "A Concept of Operations and Technology Implications for Operationally Responsive Space," Air and Power Journal, June 2006.

${ }^{19}$ Stephen, A. W. and Bonnie, J. D., "Orbital Space Plane, Past, Present, and Future," AIAA International Air and Space Symposium and Exposition: The Next 100 Years, Dayton, Ohio, AIAA Paper 2003-2718, July 14-17, 2003.

${ }^{20}$ Darby, C. L. and Rao, A. V., "Minimum-Fuel Low-Earth Orbit Aeroassisted Orbital Transfer of Small Spacecraft," Journal of Spacecraft and Rockets, Vol. 48, No. 4, May-June 2011, pp. 618-628.

${ }^{21}$ Jorris, T., Common Aero Vehicle Autonomous Reentry Trajectory Optimization Satisfying Waypoint and No-Fly Zone Constraints, Ph.D. thesis, Air Force Institute of Technology, 2004.

${ }^{22}$ Jorris, T. R. and Cobb, R. G., "Multiple Method 2-D Trajectory Optimization Satisfying Waypoints and No-Fly Zone Constraints," Journal of Guidance, Control, and Dynamics, Vol. 31, No. 3, May-June 2008, pp. 543-553.

${ }^{23}$ Jorris, T. R. and Cobb, R. G., "Three-Dimensional Trajectory Optimization Satisfying Waypoint and No-Fly Zone Constraints," Journal of Guidance, Control, and Dynamics, Vol. 32, No. 2, March-April 2009, pp. $551-572$.

${ }^{24}$ Darby, C. L., Hager, W. W., and Rao, A. V., "Direct Trajectory Optimization Using a Vaariable Low-Order Adaptive Pseudospectral Method," Journal of Spacecraft and Rockets, Vol. 48, No. 3, May-June 2011, pp. 433-445.

${ }^{25}$ Rao, A. V., Benson, D. A., Darby, C. L., Francolin, C., Patterson, M. A., Sanders, I., and Huntington, G. T., "Algorithm 902: GPOPS, A Matlab Software for Solving Multiple-Phase Optimal Control Problems Using the Gauss Pseudospectral Method," ACM Transactions on Mathematical Software, Vol. 37, No. 2, April-June 2010, Article 22, 39 pages.

${ }^{26}$ Garg, D., Patterson, M. A., Hager, W. W., Rao, A. V., Benson, D. A., and Huntington, G. T., "A Unified Framework for the Numerical Solution of Optimal Control Problems Using Pseudospectral Methods," Automatica, Vol. 46, No. 11, November 2010, pp. 1843-1851.

${ }^{27}$ Garg, D., Patterson, M. A., Darby, C. L., Francolin, C., Huntington, G. T., Hager, W. W., and Rao, A. V., "Direct Trajectory Optimization and Costate Estimation of Finite-Horizon and Infinite-Horizon Optimal Control Problems via a Radau Pseudospectral Method," Computational Optimization and Applications, Vol. 49, No. 2, June 2011, pp. 335-358.

${ }^{28}$ Vinh, N.-X., Optimal Trajectories in Atmospheric Flight, Elsevier Science, New York, 1981.

${ }^{29}$ Clarke, K., Performance Optimization of a Common Aero Vehicle Using a Legendre Pseudospectral Method, Master's thesis, Department of Aeronautics and Astronautics, Massachusetts Institute of Technology, Cambridge, Massachusetts, 2003.

${ }^{30}$ Detra, R. W., Kemp, N. H., and Riddell, F. R., "Addendum to Heat Transfer of Satellite Vehicles Re-entering the Atmosphere," Jet Propulsion, Vol. 27, 1957, pp. 1256-1257. 